\title{
"A Study of Thyroid Function Abnormalities in Patients with Chronic Kidney Disease"
}

\author{
Dr.K.Swaminathan ${ }^{1}$, Dr. S.Rajesh ${ }^{2}$, Dr.S.Avudaiappan ${ }^{3}$ \\ ${ }^{I}$ Professor, Department of General Medicine, Coimbatore Medical College \&Hospital,Coimbatore. \\ ${ }^{2}$ Senior Resident,Department of General Medicine, Coimbatore Medical College \&Hospitalcoimbatore. \\ ${ }^{3}$ Assistant Professor,Department of General Medicine, Coimbatore Medical College\&Hospital, Coimbatore.
}

\begin{abstract}
Chronic Kidney Disease is a worldwide health problem with an increasing incidence and prevalence. Abnormalities in the structure and function of the thyroid gland and in the metabolism and plasma concentration of thyroid hormones are common in patients with CKD. In view of variability of thyroid profile in CKD patients in previous studies, a prospective study of various thyroid function has been undertaken to establish a correlation if any between thyroid dysfunction and severity of renal diseases. Total number of 50 patients with Chronic Kidney Disease on conservative management fulfilling the criteria for CKD who were admitted in Department of Medicine, tertiary care hospital, during the period of July 2014-July 2015 were selected in this prospective study. The result showed that out of the 50 patients with CKD 29 patients had low T3 syndrome $(0.2-2.0 \mathrm{ng} / \mathrm{ml}$, mean 0.67) which accounts for $58 \%$ of the patients, 12 patients had low T4 syndrome $(0.5-8.5 \mu \mathrm{g} / \mathrm{ml}$, mean 5.65) which accounts for $24 \%$ of the patients and 4 patients had primary hypothyroidism TSH >20 $\mu \mathrm{IU} / \mathrm{ml}$. Excluding Primary Hypothyroidism, analysis of serum T3, T4 and TSH in the study subjects shows very high significance, $p<0.001$. Thyroid Dysfunction occurred in $66 \% \%$ of the patients with chronic kidney disease in our study, it does not indicate a state of hypothyroidism, but a reflection of the state of chronic illness/malnutrition. The low T3 state of CKD can be viewed as being protective, promoting conservation of protein. The number of patients with low T3 syndrome progressively increases with the severity of renal failure.
\end{abstract}

Keywords: chronic kidney disease, low T3syndrome, Thyroid dysfunction.

\section{Introduction}

Chronic kidney disease includes a spectrum of distinct pathophysiological processes which is associated with abnormal kidney function and a progressive reduction in glomerular filtration rate ${ }^{1,2}$.CKD is a clinical syndrome which occurs due to irreversible loss of renal function leading to metabolic, endocrine, excretory and synthetic function resulting in accumulation of non - protein nitrogenous substances which leads to metabolic derangements and ends up with distinct clinical manifestations. End stage renal disease is described as a terminal stage of chronic kidney disease that without any replacement therapy patients could not survive would result in death.

In spite of diverse etiologies, CKD is the final common pathway of irreversible loss of nephrons finally resulting in alteration of "milieu interior" affecting every system in the body including thyroid hormonal system.The functions of thyroid and kidney are interrelated ${ }^{3-6}$. The thyroid hormones are essential for growth and development of the kidney and for maintaining electrolyte and water homeostasis.So excretion of iodine is reduced in advanced renal failure. Impaired renal clearance of iodine leads to elevated serum levels of inorganic iodide that potentially blocks thyroid hormone production resulting in "Wolff Chaikoff" effect.

Chronic kidney disease is associated with thyroid function abnormalities leading to low levels of serum total and free T3 concentration and normal reverse T3 and free T4 levels. The TSH levels are almost normal in most patients and found to be in euthyroid state. Various studies have been conducted to study thyroid function abnormalities in chronic kidney disease patients. All abnormalities like hypothyroidism, hyperthyroidism and euthyroid state have been reported in the studies done previously.The relation between severity of renal failure and thyroid dysfunction is not clear. The estimated problem of hypothyroidism is between 0-9 percent in end stage renal disease. In ESRD increased prevalence of thyroid swelling (goitre) has also been noted.

\section{Aim}

To study the prevalence of low T3 Syndrome in Chronic kidney disease patients.

\section{Objectives}

1. To study thyroid function abnormalities in patients with chronic kidney disease.

2. To correlate the thyroid function abnormalities with severity of renal failure.

3. To differentiate primary hypothyroidism from thyroid dysfunction due to chronic kidney disease. 


\section{Materials And Methods}

Patients who were on conservative management fulfilling the criteria for CKD admitted in tertiary care hospital. The present study is conducted on 50 patients, who are diagnosed to have CKD and on conservative management, being admitted in Department of Medicine, during the period of July 2014 to July 2015. These samples are selected by using simple random sampling method. Statistical parameters such as mean, standard deviation (SD) and correlations are used, and parametric and non parametric tests are used for the analysis. Informed consent was obtained from all the patients. An observational, cross sectional study

\subsection{Inclusion criteria}

Patients who fulfil the criteria for CKD and who were on conservative management.

\subsection{Chronic Kidney Disease}

Presence of uraemic symptoms for 3 months or more

* Raised blood urea, serum creatinine and reduced creatinine clearance.

- Ultra sonogram evidence of CKD -Bilateral contracted kidneys - size less than 9cm, Poor corticomedullary differentiation. Supportive laboratory evidence of CKD like anaemia, change in serum electrolytes, etc.

\subsection{Exclusion criteria}

Patients on peritoneal dialysis or hemodialysis, Nephrotic range of proteinuria, Hypoalbuminemia, Other conditions like acute illness , diabetes mellitus ,recent surgery, trauma, burns, liver diseases ,drugs altering thyroid profile like amiodarone, phenytoin, beta-blocker, dopamine, steroids, estrogen pills and iodinecontaining drugs.

Detailed history and clinical examination were undertaken. The following investigations were done, urine routine and microscopic examination. Peripheral smear for anaemia, blood urea, Serum Creatinine ,Creatinine clearance (using Cockcroft — Gault formula),Serum electrolytes ,Serum calcium, phosphorous and uric acid, Serum cholesterol, 24 hours urinary protein, Serum protein (Total protein / albumin / globulin),USG abdomen for evidence of chronic kidney disease .After selection of patients, fulfilling the above criteria, about 5 $\mathrm{ml}$ of blood sample is collected in non-heparinised serum bottle and sent for thyroid profile test.

Components of thyroid profile included in our study

* Serum Triiodothyronine (T3)

* Serum thyroxine (T4)

* Serum thyroid stimulating hormone (TSH)

Quantitative determnation of T3, T4 and TSH is done by Enzyme Linked Immunosorbent Assay.

\begin{tabular}{|l|l|}
\hline THYROID PROFILE & NORMAL RANGE \\
\hline Total T3 & 0.6 to $2.1 \mathrm{ng} / \mathrm{ml}$ \\
\hline Total T4 & 5 to $13 \mathrm{micro}$ gram $/ \mathrm{dl}$ \\
\hline TSH & 0.4 to $7 \mathrm{micro} \mathrm{IU} / \mathrm{ml}$ \\
\hline
\end{tabular}

\section{Results And Analysis}

In our study 50 patients of CKD who were on conservative management fulfilling the criteria for CKD were studied, among these 34 were males and 16 were females, their age varied from 20 - 68 years.

Chart - 1 - Age distribution of cases.

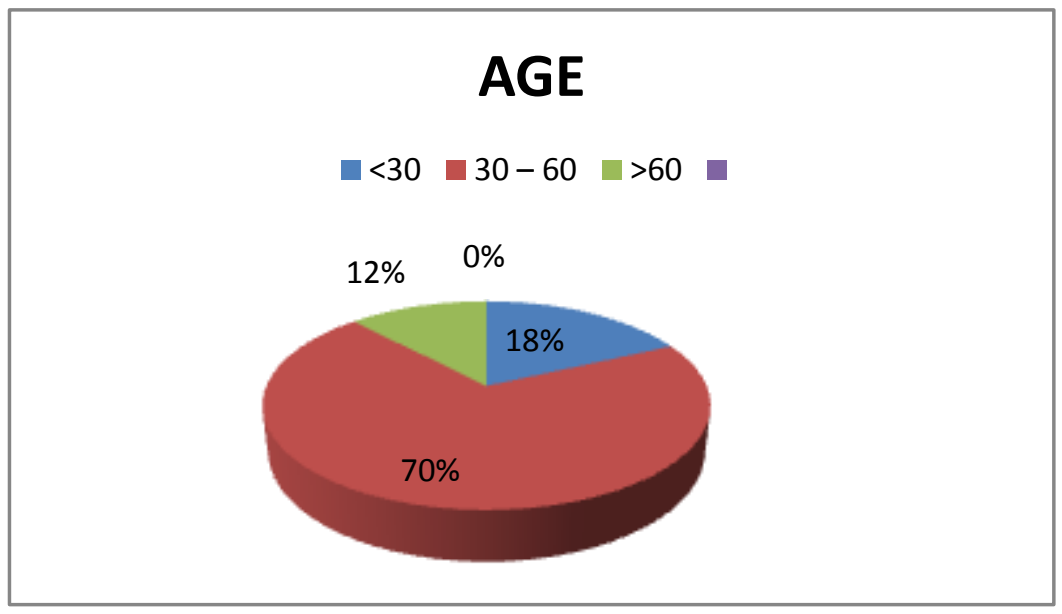


Among the 50 patients in our study, patients who were 30 years old and below were 9 constituting $18 \%$, between 31 - 60 years were 35 constituting $70 \%$ and 60 years of age and above were 6 in number constituting $12 \%$.

Chart - 2-Sex distribution of cases

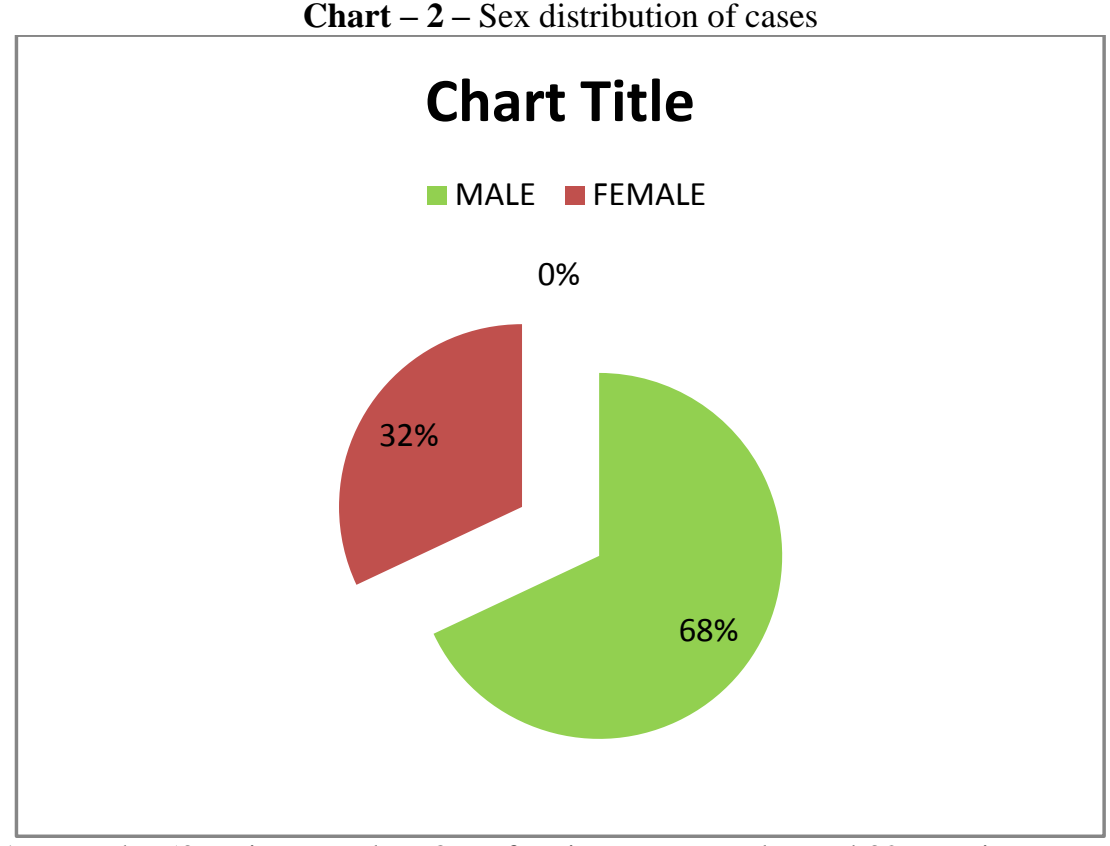

Among the 50 patients study, $68 \%$ of patients were males and $32 \%$ patients were females.

Table - 1-Distribution of creatinine clearance in ckd patients

\begin{tabular}{|l|l|l|}
\hline Creatinine clearance(ml/minute) & No. of patients & Percentage \\
\hline$<15$ & 33 & $66 \%$ \\
\hline $15-30$ & 15 & $30 \%$ \\
\hline$>30$ & 2 & $4 \%$ \\
\hline Total & 50 & \\
\hline
\end{tabular}

Chart - 3- Distribution Of Creatinine Clearance In Ckd Patients

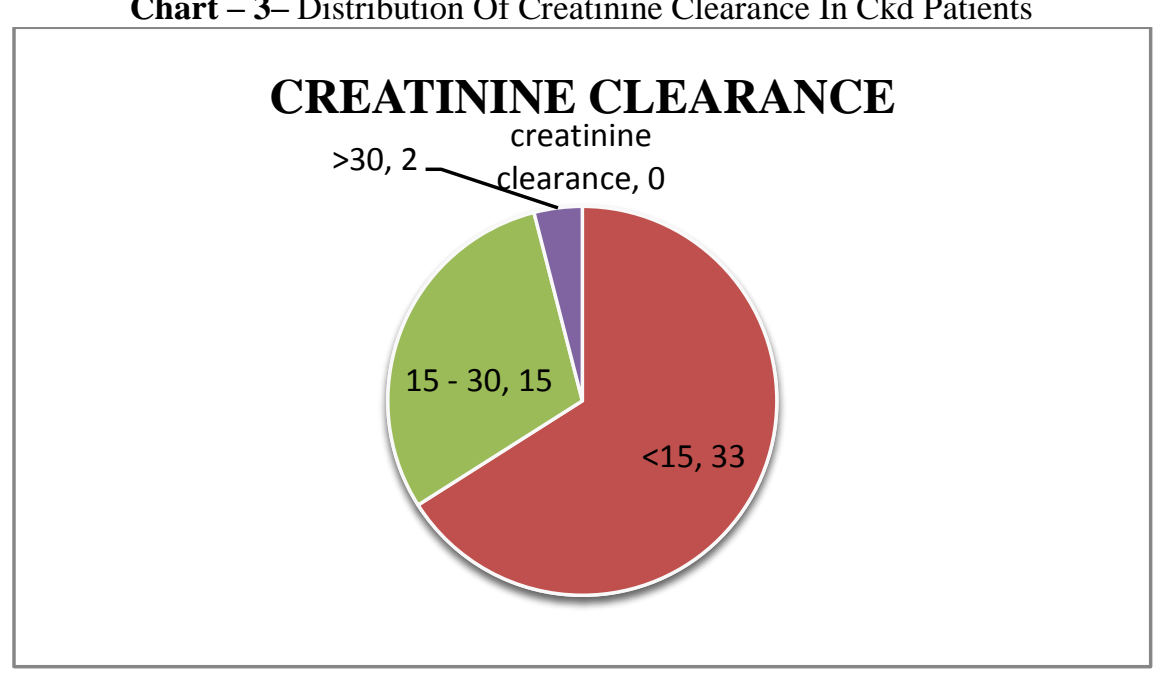

Of the 50 patients, 33 patients had GFR of less than $15 \mathrm{ml} /$ minute accounting to $66 \%$, 15 patients had GFR ranging from $15-30 \mathrm{ml} /$ minute accounting for $30 \%$ and 2 patients had GFR ranging from more than -30 $\mathrm{ml} /$ minute accounting for $4 \%$. Among the patients studied most were in the range of creatinine clearance $<15$ $\mathrm{ml} / \mathrm{minute}$. 
Chart - 4- Distribution Of Low T3 Among Various Levels Of Tsh

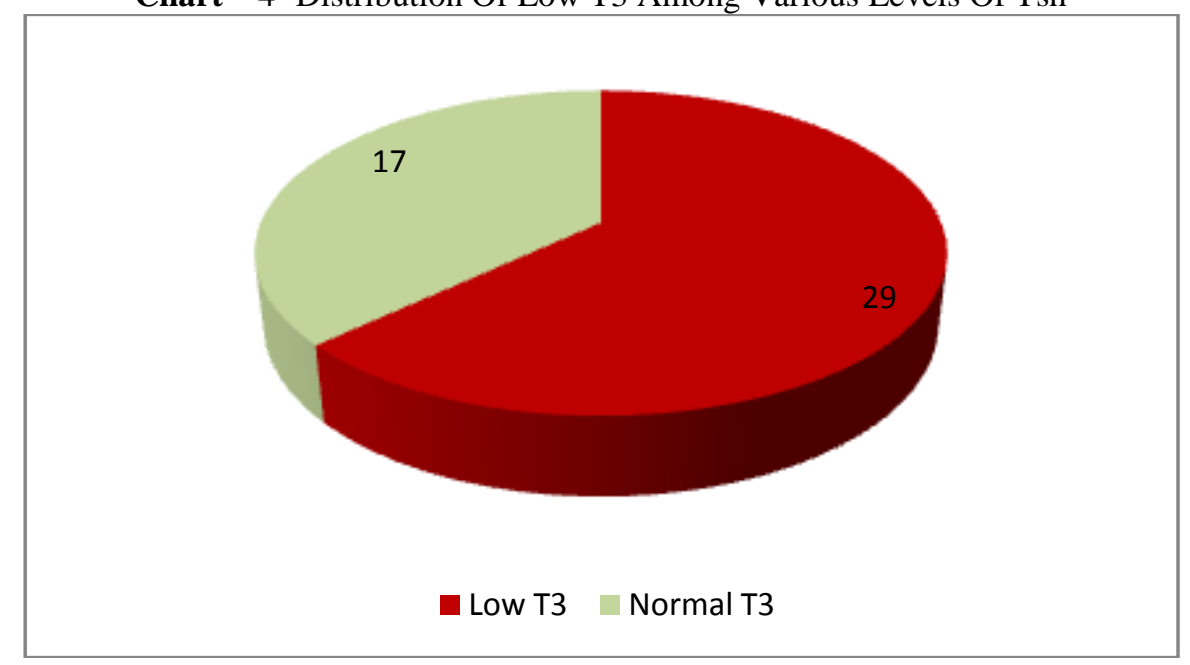

In our study out of 50 patients, 33 patients had low serum T3 levels (66\%). 4 patients among low serum T3 value, they also had low T4 and high TSH suggesting primary hypothyroidism (8\%). So excluding 4 patients of hypothyroidism 29 patients had low T3 syndrome in our study.

TABLE - 2-Distribution Of Low T4 Among Various Levels Of Tsh

\begin{tabular}{|l|l|l|}
\hline TSH level & LOW T4 & NORMAL T4 \\
\hline Normal & 12 & 34 \\
\hline High & 4 & 0 \\
\hline Total & 16 & 34 \\
\hline
\end{tabular}

16 patients had low T4 levels in our study, out of which 4 patients had low T3 and high TSH suggesting primary hypothyroidism. Excluding hypothyroidism $12(24 \%)$ patients had low T4 in our study.

Table-3: Analysis Of T3, T4, Tsh Excluding Hypothyroidism

\begin{tabular}{|l|l|l|l|}
\hline \multirow{2}{*}{$\begin{array}{l}\text { Thyroid } \\
\text { dysfunction }\end{array}$} & \multicolumn{2}{|l|}{ No. of patients with } \\
\cline { 2 - 4 } & Normal value & Low value & High value \\
\hline T3 & 17 & 29 & Nil \\
\hline T4 & 34 & 12 & Nil \\
\hline TSH & 46 & Nil & Nil \\
\hline
\end{tabular}

Chart-5: Analysis Of T3, T4, Tsh Excluding Hypothyroidism.

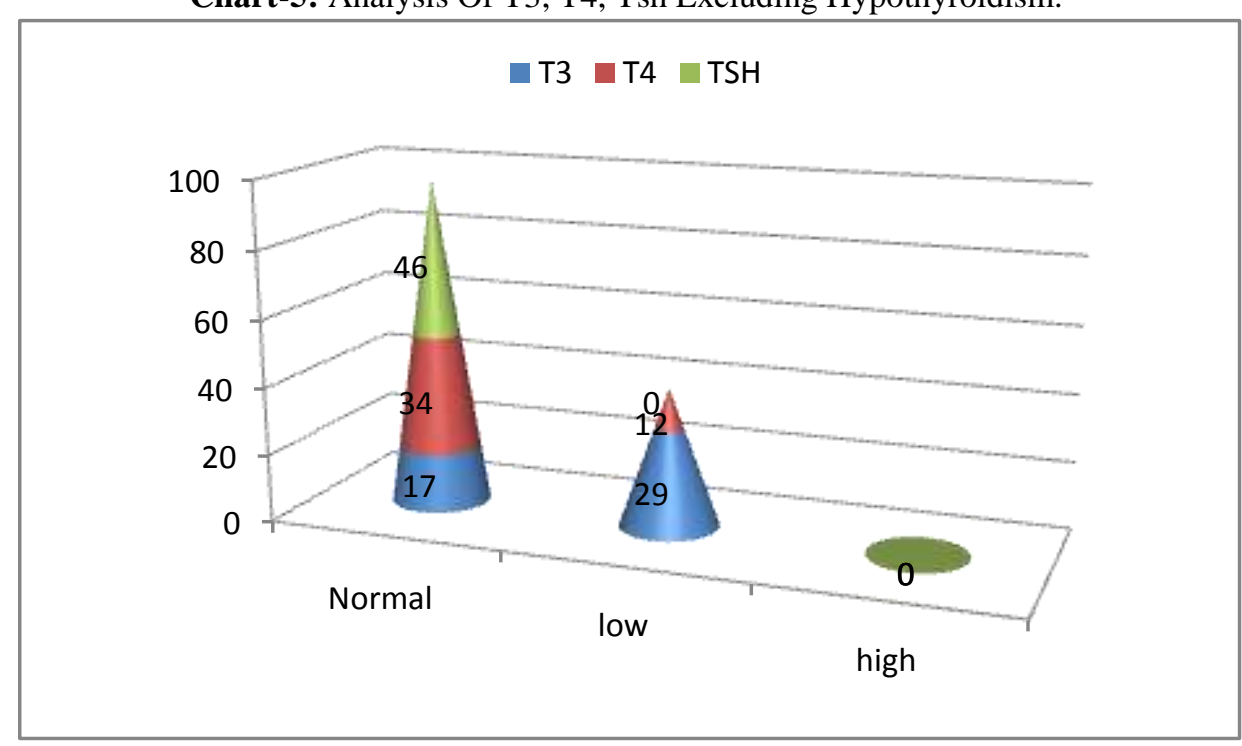


The TSH values in our study ranged from 0.6-38 micro IU/ml, the mean value being 6.494. Among 50 patients, 46 patients were in the normal range and 4 patients had high value of more than $20 \mathrm{micro}$ IU/ $\mathrm{ml}$. In patients who were in the high range 3 were males and 1 was female.

Table - 4- Analysis Of Hypothyroid Symptoms In Ckd

\begin{tabular}{|l|l|l|l|}
\hline Variants & $\begin{array}{l}\text { Total No.of } \\
\text { Patients }\end{array}$ & $\begin{array}{l}\text { No of patients with } \\
\text { symptoms }\end{array}$ & Percentage \\
\hline Low T3 & 29 & 19 & $65.51 \%$ \\
\hline Primary hypothyroidism & 4 & 4 & $100 \%$ \\
\hline CKD without thyroid dysfunction & 17 & 11 & $64.7 \%$ \\
\hline Total & 50 & 34 & \\
\hline
\end{tabular}

Out of 50 patients in our study 34 patients $(68 \%)$ had the symptoms suggestive of hypothyroidism such as tiredness, weakness, cold intolerance, dry coarse skin, constipation, hoarseness of voice, loss of hair, etc.,

Out of 29 patients who had low T3 syndrome, 19 patients had symptoms suggestive of hypothyroidism accounting for $65.5 \%$ and 4 patients among the primary hypothyroidism, all four had symptoms of hypothyroidism which accounts for $100 \%$.

Among 50 patients of CKD, 17 patients did not show any thyroid function abnormalities but out of them 11 had symptoms suggestive of hypothyroidism which accounts for $64.7 \%$.

Features of hypothyroidism such as delayed ankle jerk was present in 2 patients, out of which one were hypothyroid. Papilloedema was found in one patient who is a hypothyroid and goitre was found in one patient who is a hypothyroid. 24 hours urinary protein excretion was $<1 \mathrm{~g} /$ day in all the patients in our study.

Out of 50 patients in our study, 42 patients had anaemia, out of which 34 patients revealing normocytic normochromic anaemia in peripheral smear study and the remaining 8 patients had microcytic hypochromic anaemia.

In our study, ultrasound abdomen was done in all patients, that showed features of contracted kidney in 46 patients accounting for $92 \%$ and the remaining 4 patients had loss of cortico-medullary differentiation.

Chart - 6- Analysis Of Thyroid Dysfunction In This Study

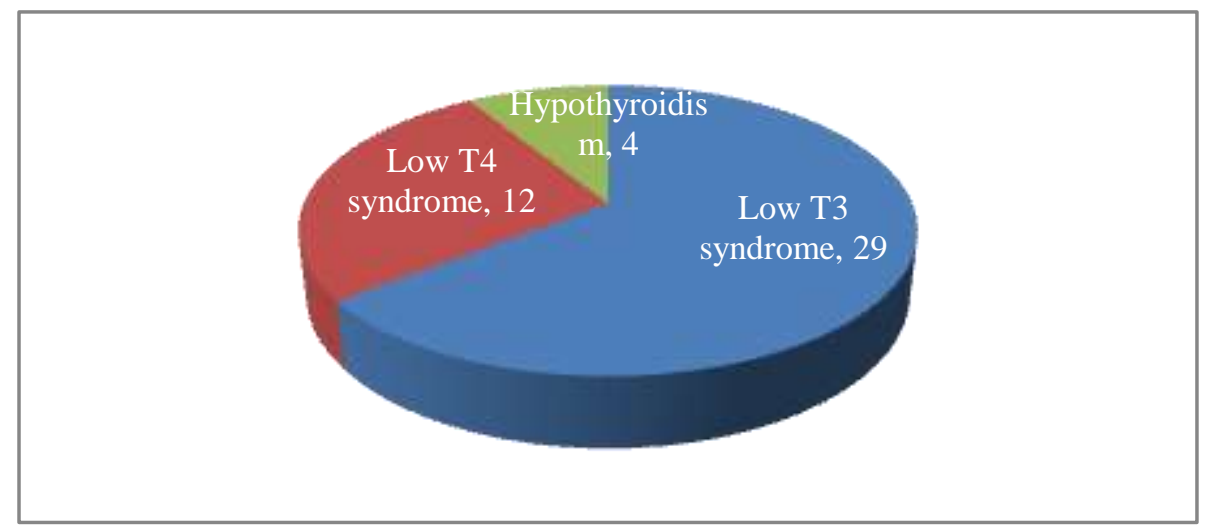

Among the patients study 58\% had low T3 syndrome, 24\% had low T4 syndrome and $8 \%$ had primary hypothyroidism

Chart-7: Distribution Of Creatinine Clearance In Patients With Low T3 Syndrome.

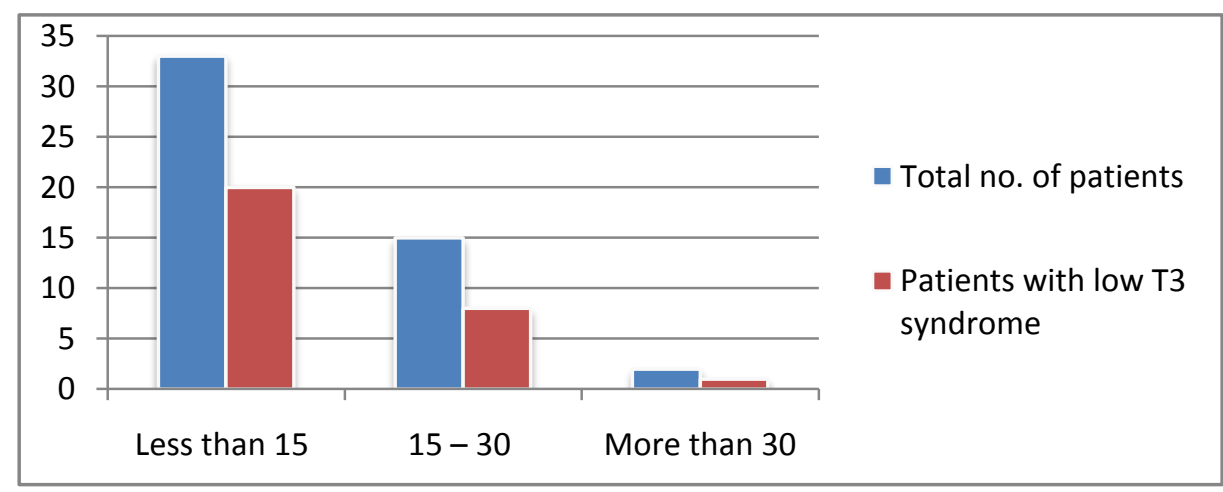


Creatinine clearance were found to be less than $15 \mathrm{ml} /$ minute in 20 patients of low T3 syndrome, 15 $30 \mathrm{ml} / \mathrm{minute}$ in 8 patients and more than $30 \mathrm{ml} / \mathrm{minute}$ in 1 patient.

Chart-8: Distribution Of Creatinine Clearance In Patients With Low T4 Syndrome.

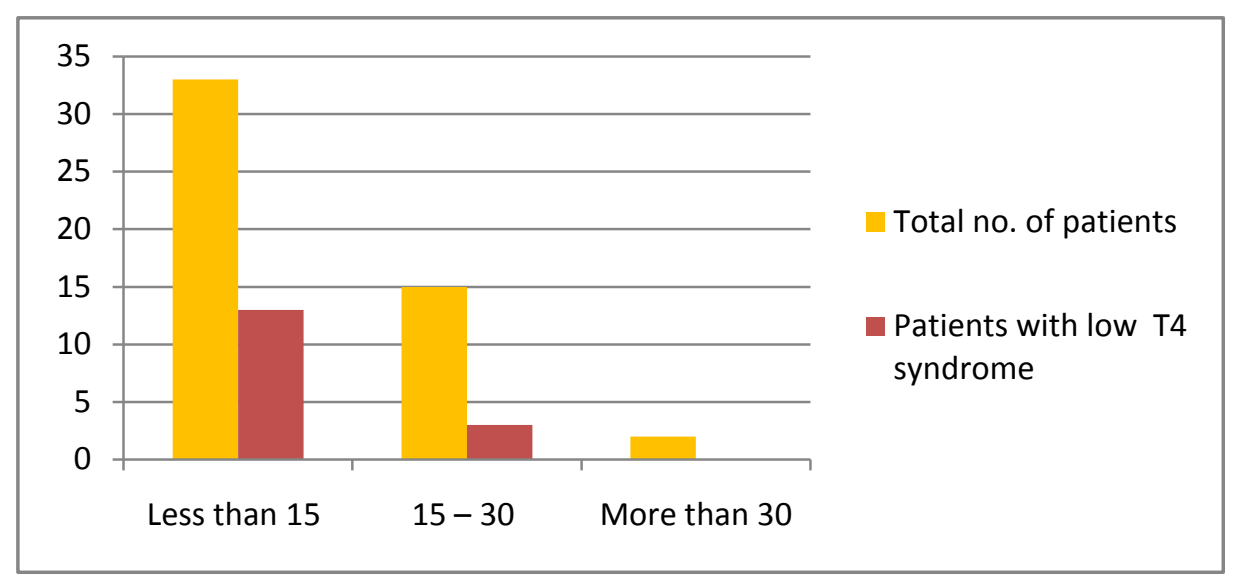

Creatinine clearance were found to be less than $15 \mathrm{ml} /$ minute in 13 patients of low T4 syndrome, 15 $30 \mathrm{ml} / \mathrm{minute}$ in 3 patients and no patients were in the range of more than $30 \mathrm{ml} / \mathrm{minute}$.

Chart -9- Age Incidence Of Low T3 Syndrome In This Study

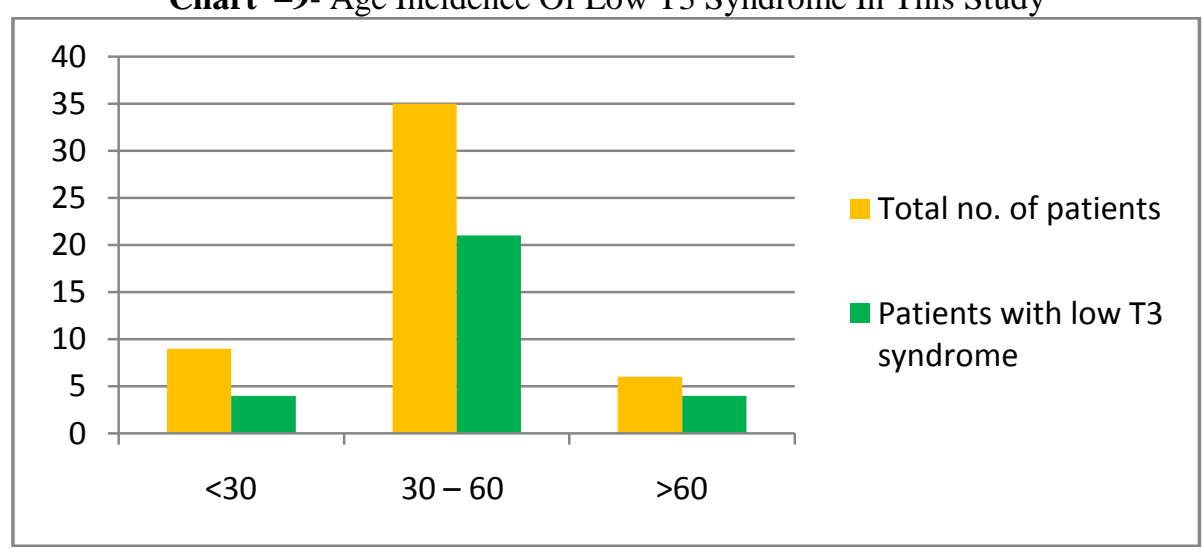

Age incidence of CKD patients with low T3 syndrome in our study showed that, CKD patients having low T3 syndrome $44.44 \%$ were less than 30 years of age, $60 \%$ were in the age group 30 - 60 years of age and $66.66 \%$ were more than 60 years of age. It tells that as the age increases number of patients with low T3 syndrome also increases.

Chart-10: Sex Incidence Of Low T3 Syndrome In This Study.

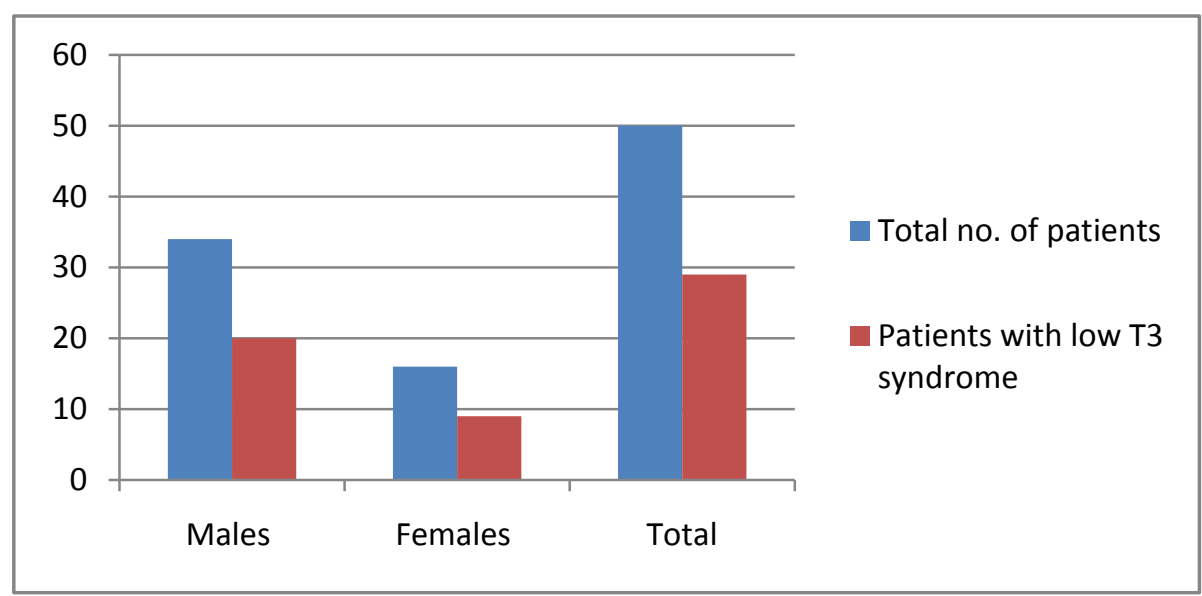


Sex incidence of CKD patients with low T3 syndrome in our study showed that $58.82 \%$ of males and $56.25 \%$ females had low T3 syndrome.

Table-5:Correlation Of Thyroid Hormones Excluding Hypothyroidism

\begin{tabular}{|c|c|c|c|c|c|c|}
\hline Thyroid hormones & $\begin{array}{l}\text { Normal } \\
\text { range }\end{array}$ & $\begin{array}{l}\text { Study } \\
\text { range }\end{array}$ & Mean & SD & $\begin{array}{l}\text { Mean } \\
\text { excluding hypothyroidism }\end{array}$ & SD \\
\hline Serum T3 & $0.6-2.1$ & $0.2-2.0$ & 0.67 & 0.53 & 0.706 & 0.53 \\
\hline Serum T4 & $5-13$ & $0.9-8.5$ & 5.65 & 2.31 & 5.94 & 2.31 \\
\hline Serum TSH & $0.4-7$ & $0.6-38$ & 6.49 & 6.99 & 4.55 & 6.99 \\
\hline
\end{tabular}

In our study T3 level ranges from $0.2-2.0 \mathrm{ng} / \mathrm{ml}$, the mean value being 0.67 . T4 level ranges from 0.9 -8.5 micro $\mathrm{g} / \mathrm{dl}$, the mean value being 5.65.TSH level ranges from 0.6 - 38 micro IU/ml, the mean value being 6.49 .

Table - 6Correlation Of Thyroid Hormones With Severity Of Renal Failure Excluding Hypothyroidism

\begin{tabular}{|c|c|c|c|c|c|c|}
\hline \multirow[t]{2}{*}{$\begin{array}{l}\text { Creatinine clearance } \\
\text { (ml/minute) }\end{array}$} & \multicolumn{2}{|l|}{ T3 } & \multicolumn{2}{|l|}{ T4 } & \multicolumn{2}{|l|}{ TSH } \\
\hline & Mean & SD & Mean & SD & Mean & SD \\
\hline$<15$ & 0.67 & 0.52 & 5.78 & 2.30 & 4.47 & 5.50 \\
\hline $15-30$ & 0.72 & 0.47 & 6.04 & 2.28 & 4.60 & 7.97 \\
\hline$>30 \mathrm{~s}$ & 1.05 & 0.73 & 7.55 & 2.63 & 5.35 & 8.10 \\
\hline
\end{tabular}

Table - 7 Incidence Of Low T3 Syndrome In Ckd

\begin{tabular}{|l|l|l|}
\hline Primary hypothyroidism & Low T3 & Normal \\
\hline No & 29 & 17 \\
\hline Yes & 4 & 0 \\
\hline
\end{tabular}

Chart - 11 Incidence Of Low T3 Syndrome In Ckd

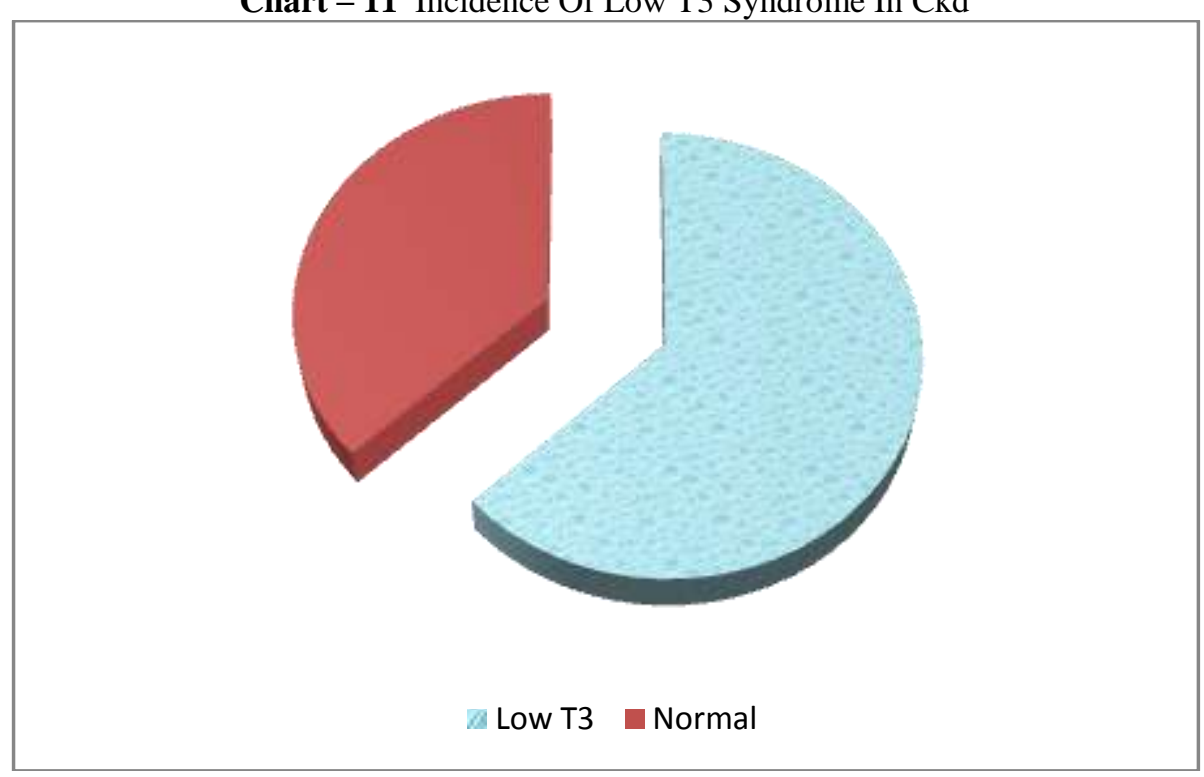

Among 50 patients included in our study 33 had low T3 level, among which 4 patients low T3 was due to primary hypothyroidism and the rest 29 patients had low T3 mainly due to influence of CKD which was also significant statistically $(\mathrm{P}<0.05)$.

\section{Discussion}

The present study was aimed at to assess the prevalence of thyroid dysfunction in CKD patients and to determine the correlation between thyroid dysfunction and severity of renal disease. Various studies was conducted about thyroid dysfunction and severity of CKD and shown different results.In our study, CKD patients only on conservative management were studied. This is because thyroid profile undergoes changes due to dialysis independent of that due to chronic kidney disease. Dialysis also changes the previous serum thyroid hormone status in patients with renal failure. Various studies have been studied by comparing CKD patients on conservative Management and patients on HD by Ramirez ${ }^{11}$ and Kayimaet $\mathrm{al}^{12}$. 
In our study 50 patients of CKD who were on conservative management fulfilling the criteria for CKD were studied, among these 50 patients, 34 were males and 16 were females, their age varied from 20 - 68 years. Among these 50 patients, patients who were 30 years old and below were 9, between 31 - 60 years were 35 and 60 years of age and above were 6 in number.Among the 50 patients study, $68 \%$ of patients were males and $32 \%$ patients were females.In our study the duration of symptoms of CKD varied from 4 months to 30 months, mean duration being 9.84 months and the creatinine clearance varied from $6 \mathrm{ml} / \mathrm{minute}-32 \mathrm{ml} / \mathrm{minute}$.

Of the 50 patients, 33 patients had GFR of less than $15 \mathrm{ml} /$ minute accounting to $66 \%$, 15 patients had GFR ranging from $15-30 \mathrm{ml} /$ minute accounting for $30 \%$ and 2 patients had GFR ranging from more than -30 $\mathrm{ml} /$ minute accounting for $4 \%$.Among the patients studied most were in the range of creatinine clearance $<15$ $\mathrm{ml} / \mathrm{minute}$. The blood urea value varied from $45-184 \mathrm{mg} / \mathrm{dl}$, the mean value being 102.12 . Among the patients studied most of them have blood urea in the range of $81-120 \mathrm{mg} / \mathrm{dl}$ Thecreatinine values varied from $3-14$ $\mathrm{mg} / \mathrm{dl}$, the mean value being 7.34. Among the patients study most of them have serum creatinine in the range of $4-8 \mathrm{mg} / \mathrm{dl}$.Serum calcium values were found to be low in 10 patients accounting for $20 \%$, normal in 28 patients accounting for $56 \%$ and high in 12 patients accounting for $24 \%$.Serum phosphorus values were found to be high in 12 patients accounting for $24 \%$ and the remaining 38 patients were found to be in normal range accounting for $76 \% .24$ hours urinary protein excretion was $<1 \mathrm{~g} /$ day in all the patients in our study.Out of 50 patients in our study, 42 patients had anaemia, out of which 34 patients revealing normocytic normochromic anaemia in peripheral smear study and the remaining 8 patients had microcytic hypochromic anaemia.

In our study, ultrasound abdomen was done in all patients, that showed features of contracted kidney in 46 patients accounting for $92 \%$ and the remaining 4 patients had loss of cortico-medullary differentiation which accounts for $8 \%$.In our study out of 50 patients, 33 patients had low serum T3 levels $(66 \%) .4$ patients among low serum T3 value, they also had low T4 and high TSH suggesting primary hypothyroidism (8\%). So excluding 4 patients of hypothyroidism 29 patients had low T3 syndrome in our study.16 patients had low T4 levels in our study, out of which 4 patients had low T3 and high TSH suggesting primary hypothyroidism. Excluding hypothyroidism $12(24 \%)$ patients had low T4 in our study.The TSH values in our study ranged from 0.6-38 micro IU/ml, the mean value being 6.494. Among 50 patients, 46 patients were in the normal range and 4 patients had high value of more than 20 micro IU/ $\mathrm{ml}$. In patients who were in the high range 3 were males and 1 was female. The all four patients with primary hypothyroidism had creatinine clearance of less than $15 \mathrm{ml} / \mathrm{min}$. It indicates the severity of renal failure in hypothyroid patients.Excluding hypothyroidism, mean TSH level in our study is within normal limits. The mean TSH levels are also within normal limits for the various ranges of GFR. But TSH level doesn't show any linear correlation with the severity of renal failure.In our study of CKD patients with low T3 syndrome, the mean TSH values in several stages of renal failure are found to be in normal range. TSH values did not show any linear correlation with glomerular filtration rate in our study. One similar study showed similar results which was conducted by Spector and Ramirez et al ${ }^{11,21}$ Dudani et al ${ }^{14}$, Karunanidhi et $\mathrm{al}^{15}$. These studies depicted abnormality in hypophyseal mechanism of TSH release in uraemic patients as the TSH response to the TRH was blunted.Another study which was conducted by Joseph et al and Hardy et $\mathrm{al}^{16,17}$ revealed low T3 T4 level with high TSH level suggesting maintenance of pituitary thyroid axis.Several studies reported in CKD patients showed low T3 values. Low T3 had been reported in Ramirez et $\mathrm{al}^{11}$, Hegedus et $\mathrm{a} 1^{10}$, Beckett et $\mathrm{al}^{18}$ PonAjil Singh et $\mathrm{al}{ }^{8}$, P Iglesias and JJ Diez ${ }^{7}$ and many others. Ramirez and Spector et a1 ${ }^{11,13}$ study showed linear correlation between mean serum $\mathrm{T} 3$ and $\mathrm{T} 4$ and severity of renal failure.Among 50 patients of CKD, 17 patients did not show any thyroid function abnormalities but out of them 11 had symptoms suggestive of hypothyroidism which accounts for $64.7 \%$.Features of hypothyroidism such as delayed ankle jerk was present in 2 patients, out of which one were hypothyroid. Papilloedema was found in one patient who is a hypothyroid and goitre was found in one patient who is a hypothyroid.Previous studies by Quionverdeet $\mathrm{a} 1^{20}$ reported high preponderance of hypothyroidism in CKD. It was estimated to be about $5 \%$ in patients with terminal stage of renal failure.Elaborated study by Kaptein et $\mathrm{al}^{5,21}$ estimated the prevalence of primary hypothyroidism was about 2.5 times much frequent in chronic kidney disease and dialysis. The hypothyroidism in CKD was estimated to range between 0 and $9.5 \%$ Kaptein study also estimated the presence of antithyroid antibody titer in $6.7 \%$ of CKD.In our study, hypothyroidism is present in $8 \%$ of the patients but doesn't correlate with the severity of the renal failure. The symptoms of hypothyroidism were distributed equally in both hypothyroid and CKD patients in our study.

So, diagnosis of hypothyroidism in CKD mainly rest on TSH level which should be very high $(>20$ $\mu \mathrm{IU} / \mathrm{dl}$ ) with low serum T4. In this study none of the patients had clinical or biochemical features of hyperthyroidism. Age incidence of CKD patients with low T3 syndrome in our study showed that, CKD patients having low T3 syndrome $44.44 \%$ were less than 30 years of age, $60 \%$ were in the age group 30 - 60 years of age and $66.66 \%$ were more than 60 years of age. It tells that as the age increases number of patients with low T3 syndrome also increases. Among the patients study 58\% had low T3 syndrome, 24\% had low T4 syndrome and $8 \%$ had primary hypothyroidism. Creatinine clearance were found to be less than $15 \mathrm{ml} / \mathrm{minute}$ in 20 patients of low T3 syndrome, $15-30 \mathrm{ml} /$ minute in 8 patients and me than $30 \mathrm{ml} /$ minute in 1 patient.Creatinine clearance 
were found to be less than $15 \mathrm{ml} /$ minute in 13 patients of low T4 syndrome, $15-30 \mathrm{ml} /$ minute in 3 patients and no patients were in the range of more than $30 \mathrm{ml} /$ minute.As with other studies, mean T3 level in our study was reduced in GFR less than $15 \mathrm{ml} / \mathrm{min}$. In patients with low GFR, T3 level was found to be reduced and it shows there was direct linear relationship between T3 level and GFR, which is consistent with Avinashi et al study.

\section{Conclusion}

$>$ In my study population, $50 \mathrm{CKD}$ patients who were on conservative management were studied. Among them $66 \%$ of the patients had low T3 values.

> The change in the serum levels of $\mathrm{T} 3$ and $\mathrm{T} 4$ in patients with CKD can be considered as being protective, promoting conservation of protein.

$>$ There is progressive increase in the number of patients with Low T3 and T4 syndrome with the severity of renal failure.

$>$ There is increase in incidence of hypothyroidism in patients with chronic kidney disease.

$>$ Excluding hypothyroidism T3 level is found to be low in 58\% of the patients and T4 level is low in $24 \%$ of the patients. .

$>$ As the age increases there is increase in incidence of Low T3 syndrome in patients with CKD.

$>$ In patients with low GFR the serum T3 level was found to be decreased. This shows a direct linear relationship between GFR and T3 level.

\section{Limitations Of This Study}

Thyroid dysfunction was studied in patients with CKD irrespective of the etiology of CKD therefore individual correlation of the etiology of CKD with thyroid dysfunction could not be studied. Thyroid dysfunction was not studied in patients on dialysis, as dialysis itself affects the thyroid profile independently of CKD.

\section{Bibiography}

[1]. Andrew S. Levey, Josef Coresh, Ethan Balk, Annamaria T. Kausz, Ronald D. Perrone. National Kidney Foundation Practice Guidelines for Chronic Kidney Disease: Evaluation, Classification, and Stratifiction. MD Ann Intern Med. 2003;139:137-147.

[2]. Joanne M.Bargman, Karl S.Korecki. Chronic kidney disease. In: Dan L.Lango, Anthony S.Fauci, Dennis Kasper et al. Harrison's Principles of Internal Medicine, Vol. 2, 18th edn., 2011; McGraw Hill, USA, pp. 2289-2293; 2308-2313.

[3]. Feinstein EI, Kaptein EM, Nicoloff JT \&Massry SG. Thyroid function in patients with nephrotic syndrome and normal renal function. American Journal of Nephrology $1982270 Đ 76$.

[4]. Kaptein EM, Quion-Verde H \&Massry SG. Hemodynamic effects of thyroid hormone. Contributions to Nephrology 198441 $151 Đ 159$.

[5]. Kaptein EM. Thyroid function in renal failure. Contributions to Nephrology $19865064 \nsupseteq 72$.

[6]. Robert W Schrier. Abnormalities in the thyroid gland and hypothalamo pituitary thyroid axis in patients with CKD - Diseases of the kidney and urinary tract, eighth edition 2007; volume 3: page number 2518.

[7]. P Iglesias and J JDi'Ez. Thyroid dysfunction and kidney disease. European Journal of Endocrinology (2009) 160: 503-515.

[8]. J. L. Jameson and A. P. Weetman, Harrison's Principles of Internal Medicine 18th Edition, Disorders of the Thyroid Gland.

[9]. PonAjil Singh, Zachariah Bobby, N. Selvaraj and R. Vinayagamoorthi. An evaluation of thyroid hormone status and oxidative stress in undialyzed chronic renal failure patients. Indian J PhysiolPharmacol 2006; 50 (3): 279-284.

[10]. Hegedus L et al. Thyroid gland volume and serum concentrations of thyroid hormone in chronic renal failure. Nephron, $1985 ; 171-4$.

[11]. Ramirez $\mathrm{G}$ et al. Thyroid abnormalities in renal failure. A study of 53 patients on chronic dialysis. Ann Internal Medicine, 1973; 79 , 500-4.

[12]. Kayima JK et al. Thyroid hormones profile in patients with chronic renal failure on conservative management and regular hemodialysis. East Afr Med J, 1992; 69: 333-6.

[13]. Spector DA et al. Thyroid function and metabolic rate in chronic renal failure. Ann Intern Med. 1976; 85: 724-30.

[14]. Dudani RA et al. Thyroid dysfunction in Ureaemia J Assoc Physicians India. 1981; 29: 1037-40.

[15]. KarunanidhiA et al. Thyroid function in patients with chronic renal failure. Indian J Med Research, $1979 ; 69: 792-7$.

[16]. Hardy MJ et al. Pituitary — Thyroid function in chronic renal failure assessed by a highly sensitive thyrotropin assay. J Din EndocrinolMetab, 1988; 66: 233-6.

[17]. Joseph LJ et al. Measurement of serum thyrotropin levels using sensitive immunoradiometri assays in patients with chronic renal failure alterations suggesting an intact pituitary thyroid axis. Thyroidology, 1993; 5: 35- 9 .

[18]. Beckett $G$ et al. Thyroid status in patient with chronic renal failure. Clinical Nephrology, 1983; $19: 172-8$.

[19]. Weissel M. Evaluation of thyroid function in non thyroid diseases. Acta Med Austrica, 1978; 5: 100-2.

[20]. Quion-verde et al. Prevalence of thyroid disease in chronic renal failure and dialysis patients. IXt1' mtCongr of Nephrol, 1984 ; 120.

[21]. Kaptein E et al. The Thyroid in end stage renal diseases, Medicine, 1988;187-97. 